\title{
A Criatura contra o Financiador
}

The Creature against the Financer

Allen Silva ${ }^{1}$; Diógenes Fernandes ${ }^{2}$; Otávio França ${ }^{3}$.

${ }^{1}$ E-mail: allen.silva@gmail.com Universidade Candido Mendes, Brasil (UCAM)

${ }^{2}$ E-mail: diogenesivo@gmail.com Universidade Candido Mendes, Brasil (UCAM)

${ }^{3}$ E-mail: franca@mfd.adv.br Universidade Candido Mendes, Brasil (UCAM)
Resumo: O Estado, no ímpeto de contribuir com o desenvolvimento económico, promulga leis atrativas para que o empresário financie a pesquisa. Por sua vez, a falta de controlo e conhecimento da pesquisa financiada, gera o risco da inovação financiada ser prejudicial ao próprio empresário.

Palavras-chave: Estado; Lei; Avanço; Inovação; Malware.

\begin{abstract}
Aiming to contribute for the economical development, the State proclaims attractive laws for the businessman in order to finance the research. In turn, the lack of control and knowledge of the funded research, generates a risk of failure to the financed innovation as well as to the entrepreneur himself.
\end{abstract}

Keywords: State; Law, Advance; Innovation; Malware. 


\section{pontěditora}

\section{INTRODUÇÃO}

O presente artigo procura, através do método de pesquisa bibliográfica, demonstrar a modificação do paradigma no que tange ao controlo do produto final de uma pesquisa incentivada ou beneficiada nos termos da Lei de Inovação e do Bem.

O país que, no período de 2000 a 2010, criou 75.517 leis, no total de 18 leis por dia desde o ano 2000, tenta inovar com mais uma lei para regulamentar e incentivar a inovação no Brasil. A Lei no 10.973, de 2 de dezembro de 2004, dispôs sobre incentivos à inovação e à pesquisa científica e tecnológica no ambiente produtivo, sendo alterada pela Lei $\mathrm{n}^{\mathrm{o}}$ 13.243, de 11 de janeiro de 2016, muito em função da Emenda Constitucional $\mathrm{n}^{\circ} 85$, de 26 de fevereiro de 2015.

Como a maioria das leis promulgadas em solo tupiniquim, a falta de clareza e agilidade dos órgãos estatais, não gerou uma alteração tão inovadora no mercado como pretendeu o legislador. Como o bom exemplo do pato - que nada, voa e anda mal - a Lei da Inovação não conseguiu melhorar o panorama inovador no Brasil, mudou a regra do jogo no meio de uma crise e não trouxe consigo um aprimoramento dos setores públicos que irão auxiliar nesse processo de apoio à pesquisa.

De acordo com a Pintec (Pesquisa de Inovação Tecnológica, divulgada pelo IBGE), a quantidade de companhias que declararam ter introduzido pelo menos uma inovação em seus projetos aumentou apenas 5\%, passando de 33,4\%, entre 2003 e 2005, para 38,4\%, entre 2006 e 2008, segundo o último balanço.

No presente trabalho, partimos de um caso concreto para ilustrar como o benefício fiscal, que visa fomentar a inovação, pode gerar um prejuízo financeiro para outros ramos empresariais.

\section{O CONTROLO}

O controlo social faz-se presente desde que os seres humanos passaram a viver em comunidades, sociedades. O Estado nasce com a prerrogativa de implementar o controlo em que habita seus domínios. A necessidade de manutenção da ordem e a imposição de 


\section{pontěditora}

determinados comportamentos coadunaram para a existência do controlo social. A criação da propriedade privada gera a noção de Estado, este que garante sua manutenção e a imposição dogmática e doutrinária através do controlo exercido.

Assim, o controlo surgiu como uma necessidade de regular o poder. Seria leviano pensar que o detentor do domínio bélico e económico fizesse uso de um auto-limite, de modo a não provocar um desequilíbrio social ou que, pura e simplesmente, busque pautar as suas ações pelo caminho do justo e da ética.

Em termos estatais, o controlo caracteriza-se como sendo uma espécie de instituto de direito público, levando a uma diferenciação entre os órgãos e as vontades envolvidas. Para que se tenha o mínimo de êxito, o órgão controlador tem de ser diferente do controlado. A abrangência do termo controlo também abarca o seu viés social, onde o grupo dominador mantém o dominado sob controlo, enquanto este último é sugado.

Em teoria, o iluminismo tinha o fito de libertar o homem ${ }^{1}$ (rectius: ser humano), seja no aspeto económico ou social. Portanto, o Estado (monarca) e todo o seu poderio absolutista deveriam ser relegados a um plano inferior ao indivíduo, notadamente respeitando a autonomia de vontade deste último.

Assim, a razão e a cientificidade deveriam sobrepujar a ignorância e o arbítrio. Neste particular, sobre a derrota das trevas pela luz, na saída de um período obscuro dos agouros para a racionalidade, faz-se oportuna a citação a Immanuel Kant:

Esclarecimento (Aufklärung) significa a saída do homem de sua menoridade, pela qual ele próprio é responsável. A menoridade é a incapacidade de se servir de seu próprio entendimento sem a tutela de um outro. É a si próprio que se deve atribuir essa menoridade, uma vez que ela não resulta da falta de entendimento, mas da falta de resolução e de coragem necessárias para utilizar seu entendimento sem a tutela de outro. Sapere aude! (Ousa saber!) Tenha a coragem de te servir de teu próprio entendimento, tal é portanto a divisa do Esclarecimento. Preguiça e covardia são as causas que explicam por que uma grande parte dos seres humanos, mesmo muito após a natureza tê-los declarado livres da orientação alheia ainda permanecem, com gosto e por toda a vida, na condição de menoridade. As mesmas causas explicam por

\footnotetext{
${ }^{1}$ Declaração de Direitos do Homem e do Cidadão: Art. $1^{\circ}$. Os homens nascem e são livres e iguais em direitos. As distinções sociais só podem fundamentar-se na utilidade comum. http://www.direitoshumanos.usp.br/index.php/Documentos-anteriores-\%C3\%A0cria\%C3\%A7\%C3\%A3o-da-Sociedade-das-Na\%C3\%A7\%C3\%B5es-at\%C3\%A9-1919/declaracao-dedireitos-do-homem-e-do-cidadao-1789.html (acesso a 9 de abril de 2016).
} 


\section{pontěditora}

que parece tão fácil outros afirmarem-se como seus tutores. É tão confortável ser menor! Tenho à disposição um pastor que tem consciência por mim, um médico que me prescreve uma dieta então não preciso me esforçar. Não me é necessário pensar, quando posso pagar; outros assumirão a tarefa espinhosa por mim. "Resposta à pergunta: O que é o Esclarecimento? ${ }^{2}$

Desta forma, o controlo é exercido pelo Estado no intuito de manutenção da ordem através da imposição.

Todavia, a evolução presenciada no século XX possibilitou uma grande inovação nos meios de comunicação e na forma de interação entre os seres humanos, esta ocasionada pela internet que, como meio de comunicação instantâneo, causou fissuras nos tradicionais processos de comunicação conhecidos até os anos que encerraram o século XX. O seu uso permite que os seus indivíduos possam ser sujeitos ativos no processo de emissão e geração de conteúdo.

O controlo social pessoal é o realizado em ambiente virtual onde as pessoas se controlam diariamente. E, por isso, nasce a necessidade de haver a privacidade dos indivíduos, pois estes devem contar com um freio à invasão de terceiros e ao poder e domínio Estatal. A privacidade dos seres humanos tem o condão de impedir o acesso de terceiros e limitar o poder do Estado e será oponível, inclusive a esse.

No Brasil, a Constituição advinda da redemocratização garante ao Estado o poder de controlar. No entanto, dá aos cidadãos a garantia de sua privacidade, haja vista a previsão Constitucional que segue:

[...] representantes do povo brasileiro, reunidos em Assembléia Nacional Constituinte para instituir um Estado Democrático, destinado a assegurar o exercício dos direitos sociais e individuais, a liberdade, a segurança, o bemestar, o desenvolvimento, a igualdade e a justiça como valores supremos de uma sociedade fraterna, pluralista e sem preconceitos, fundada na harmonia social e comprometida, na ordem interna e internacional, com a solução pacífica das controvérsias [...].

No mesmo diploma legal foi instituído que:

\footnotetext{
2 Immanuel Kant, 1985, Dialética do Esclarecimento, Tradução de Guido Antonio de Almeida, Rio de Janeiro: Jorge Zahar Editor.
} 


\title{
pontěditora
}

\begin{abstract}
Art $5^{\circ}$ Todos são iguais perante a lei, sem distinção de qualquer natureza, garantindo-se aos brasileiros e aos estrangeiros residentes no País a inviolabilidade do direito à vida, à liberdade, à igualdade, à segurança e à propriedade, nos termos seguintes:

$X$ - são invioláveis a intimidade, a vida privada, a honra e a imagem das pessoas, assegurado o direito a indenização pelo dano material ou moral decorrente de sua violação;
\end{abstract}

Conforme já mencionado, a criação e a proliferação da rede mundial dos computadores, determinou a necessidade de adaptar e adequar a legislação Pátria à Era cibernética, assim, visando aproximar a legislação para o quotidiano digital que vive o Brasil, foi promulgada a Lei $\mathrm{n}^{\circ} 12.965$, de 23 de abril de 2014, que normalizou aspetos morais que hoje em dia necessitam estar dispostos na forma de lei:

\footnotetext{
Art. $3^{\circ}$ A disciplina do uso da internet no Brasil tem os seguintes princípios: I - garantia da liberdade de expressão, comunicação e manifestação de pensamento, nos termos da Constituição Federal;

II - proteção da privacidade;

III - proteção dos dados pessoais, na forma da lei;

IV - preservação e garantia da neutralidade de rede;

$V$ - preservação da estabilidade, segurança e funcionalidade da rede, por meio de medidas técnicas compatíveis com os padrões internacionais e pelo estímulo ao uso de boas práticas;

VI - responsabilização dos agentes de acordo com suas atividades, nos termos da lei;

VII - preservação da natureza participativa da rede;

VIII - liberdade dos modelos de negócios promovidos na internet, desde que não conflitem com os demais princípios estabelecidos nesta Lei.
}

Com a proliferação da internet, logo surgiram espaços de discussão como fóruns, chats, blogs, e os sites de redes sociais. E isso ocasionou um intenso controlo social gerado por uma excessiva exposição pessoal nas redes sociais. Esse realizado pelos pares, internautas, que se valem da "máscara" para realizar os seus julgamentos sem qualquer filtro ou pudor.

Nessas áreas, com peculiaridades ora públicas, ora privadas, o público passou a divulgar em larga escala, as suas rotinas, com imagens, vídeos e textos. Nos sites de redes sociais não basta interagir com os outros ou ter acesso a informações diversas, é praticamente 
necessário transformar-se na própria informação, como se cada usuário, cada perfil, fosse um veículo de comunicação autónomo. 


\section{pontěditora}

A busca por conexões é uma forma de tornar-se um expoente de opinião, criando-se um personagem, este emissor de mensagens das mais variadas matizes. Mas, há de se ver que a credibilidade do emissor da mensagem, em alguns casos, advém de simpatias por ideais em comum.

Em tempos de liberdade, não se discute amplamente a potencialidade da internet na identificação de usuários por meio daquilo que publicam. Mas em países com regime ditatorial, as comunicações mantidas pela internet são inteiramente fiscalizadas.

Graças a uma tecnologia da comunicação é possível que qualquer usuário, com conhecimento avançado em programação, vigie outro usuário por aquilo que ele publica. A vigilância também ocorre entre todos os usuários - especialmente nos espaços públicos das redes sociais online.

É interessante mencionar que a rede mundial de computadores fora disponibilizada com o intuito de permanecer um ambiente descaracterizado da vida real, ou seja, em que os usuários se valessem do anonimato para realizar a sua navegação. E, a modificação paradigmática impossibilitou a manutenção de tal princípio.

Assim, existe a possibilidade de encontrar um usuário e de ligá-lo às suas preferências, ainda que isso viole sua privacidade; Pois, muitas vezes, o próprio usuário opta por tornar as suas publicações públicas aos membros da sua rede e não se consegue mensurar a dimensão que sua participação na rede pode atingir, não temos a real consciência dos efeitos de determinada publicação, ou não se sabe determinar sobre a possível vigilância que possa ocorrer.

\section{A CRIAÇÃO VOLTA-SE CONTRA O FINANCIADOR}

Conforme o relatório "Números de investimento em media online 2013-2014", disponível no site da IAB Brasil ${ }^{3}$, em território brasileiro "o mercado publicitário na Internet em 2013 atingiu 25.9\% de crescimento e obteve aproximadamente R\$ 5,75

\footnotetext{
${ }^{3}$ O IAB Brasil promove o intercâmbio - nacional e internacional - de experiências e conhecimentos técnicos através de cursos, palestras, publicações, artigos e pesquisas cujos resultados sejam de interesse comum ao mercado. 


\section{pontěditora}

bilhões, consolidando-se como o segundo maior meio em participação no bolo publicitário, ultrapassando jornais e ficando atrás apenas da TV”"4.

Por sua vez, a agência de marketing social We Are Social divulgou o relatório Digital, Social e Mobile de 2015, que mostra as estatísticas completas do uso da internet em 2014. No caso específico do Brasil, ficou demonstrado que a população brasileira é uma das maiores usuárias da internet, principalmente a internet mobile - o que aumenta aproximação com a tecnologia.

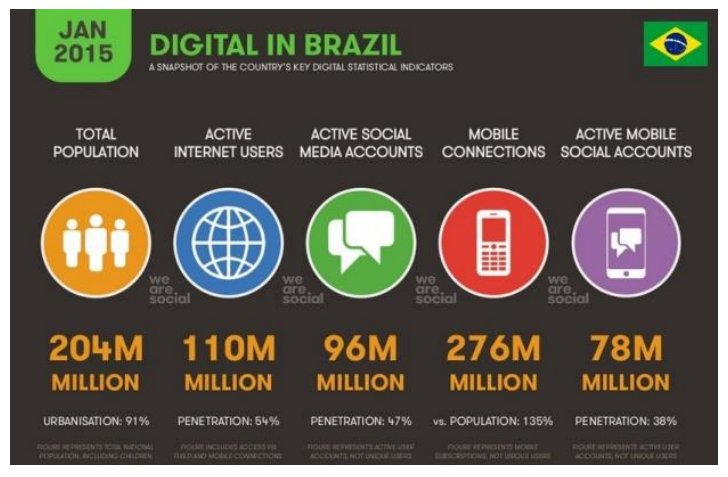

E ainda, retornando ao relatório do IAB Brasil, o consumo semanal de media, 14 horas ou mais por semana, aumentou $38 \%$ no item "internet (navegando)". Portanto, somando os dados chega-se a conclusão que comercializar um espaço no site se tornou uma fonte de renda.

Ocorre que no ano de 2002, Henrik Aasted Sorensen criou o plug-in Adblock. Passado 4 (quatro) anos, Wladimir Palant aprimorou o programa e lançou o AdBlock Plus e, em menos de um ano depois, o plug-in tornou-se um dos mais adquiridos pelos usuários do navegador Firefox ${ }^{5}$. Segundo consta no site da Google, o AdBlock é a extensão mais popular do navegador Chrome $^{6}$ :

Com mais de 200 milhões de downloads e contando, AdBlock é uma extensão livre que bloqueia anúncios intrusivos em páginas web, enquanto ajuda a proteger contra malware e rastreamento. Nós mencionamos que o Adblock é gratuito? As doações são incentivadas, mas nunca são obrigatórias. ${ }^{7}$

\footnotetext{
${ }^{4}$ Disponível em: <http://iabbrasil.net/conteudos/pesquisas >. Acesso em 17 jul. 2017.

${ }^{5}$ Navegador desenvolvido pela Mozilla Corporation (US).

${ }^{6}$ Navegador desenvolvido pela Google (US).

${ }^{7}$ https://chrome.google.com/webstore/detail/adblock/gighmmpiobklfepjocnamgkkbiglidom?hl=pt-BR
} 


\section{pontěditora}

Para um melhor entendimento do estudo, é necessário explicar que o AdBlock tem a função de tornar a navegação mais limpa, ou seja, ao aceder um site de um jornal, o usuário não visualizará os anúncios disponíveis naquela página, conforme os exemplos abaixo:
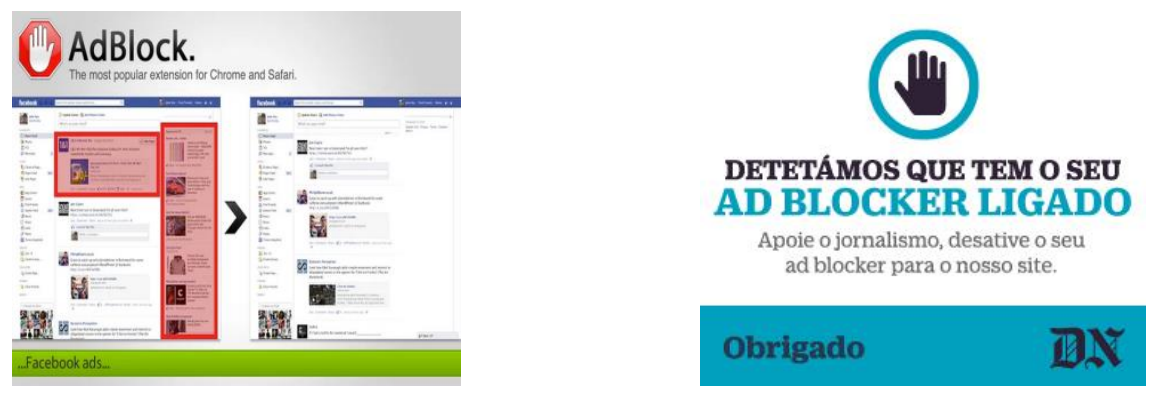

Portanto, com a instalação do plug-in, automaticamente toda a publicidade (ou boa parte dela) é excluída do campo visual do usuário. Apesar do seu desenvolvimento ter sido sem auxílio financeiro, e que para adquirir o plug-in o usuário não arca com nenhum custo, utilizo o AdBlock como acessório para demonstrar como novas tecnologias que beneficiam muitos usuários (o que se vê), geram um prejuízo (o que não se vê) enorme para os sites de jornais e demais páginas que contenham anúncios e são bloqueadas pelo plug-in AdBlock.

A crescente preocupação pela privacidade no ambiente digital, gera produtos inovadores, mas conflituantes com a finalidade do incentivo fiscal para inovação, qual seja essencialmente o desenvolvimento económico.

\section{O ESTADO EMPREENDEDOR}

O Estado com o ímpeto de promover o desenvolvimento económico vem intervindo cada vez mais no quotidiano empresarial. Tal intervenção é legal e tem base constitucional, afinal a Constituição dispõe a proteção da livre iniciativa e dos demais direitos previstos no artigo 170, da Constituição Federal.

Em termos comparativos, o Brasil segue uma estratégia adotada por outros Estados estrangeiros, podemos constatar que esse modelo funciona muito bem, vide o caso da Apple, Google e outras empresas que se serviram do apoio estatal para financiar as suas 


\section{pontěditora}

pesquisas em troca da produção de produtos que tivessem serventia para fins governamentais, mas, também, para fins comerciais, consequentemente, gerando lucros milionários para as empresas patrocinadas.

Em termos nacionais, temos uma forte evolução desse processo empreendedor estatal na Era Vargas, ao criar as primeiras empresas estatais, e já em um tempo mais próximo, com a criação dos "campeões nacionais".

Além disso, temos como as Agências de Fomento Estaduais, que dão amparo a projetos que contribuam com o desenvolvimento local, em troca de royalties ${ }^{9}$. Por lógica, todas essas formas de fomento, intervenção ou contribuição surgem após a promulgação de uma lei.

Recentemente a Lei da Inovação teve um novo marco e foi encorpada com a promulgação de outras leis que prevêem benefícios fiscais para o empresário que destine alguma verba para a pesquisa:

a) financiamento não reembolsável para pesquisa acadêmica através das Fundações Estaduais de Amparo à Pesquisa

b) subvenção;

c) financiamento reembolsável em condições favorecidas (taxas menores, prazos maiores etc.);

d) participação no capital do empreendimento;

e) capital empreendedor para desenvolvimento de pequenas empresas de base tecnológica;

Os novos instrumentos legais ampliaram o alcance dos programas de financiamento à P\&D. Com os novos instrumentos legais (especialmente Lei de Inovação e Lei do Bem) e com o aumento na execução dos Fundos Setoriais, a FINEP apoiou 923 empresas em quatro anos (2005/out.2008). Considerando o edital de subvenção de novembro de 2008 a FINEP financiou em quatro anos 1.132 empresas.

Ocorre que a falta de cautela no produto gerado por aquela pesquisa ${ }^{10}$, pode ocasionar

\footnotetext{
8 Tal nomenclatura foi utilizada pela primeira vez pelo EUA.

9 Aqui não vamos entrar no mérito sobre a forma e qual a rentabilidade desses royalties.

${ }^{10}$ Aqui adotaremos o termo "pesquisa" de forma genérica, visto que trataremos "pesquisa" como sinónimo de "pesquisa de base", assim como "pesquisa" o desenvolvimento de um aplicativo. 


\section{pontěditora}

num aplicativo extremamente popular e, por conseguinte, utilizado por milhares de usuários (o que se vê), mas que gera um enorme prejuízo para um determinado ramo empresarial (o que não se vê).

A Lei $n^{\circ}$ 8.010/1990 dispõe sobre importações de bens destinados à pesquisa científica e tecnológica, estabelece que são isentas dos impostos de importação e sobre produtos industrializados e do adicional ao frete para renovação da marinha mercante as importações de máquinas, equipamentos, aparelhos e instrumentos, bem como suas partes e peças de reposição, acessórios, matérias-primas e produtos intermediários, destinados à pesquisa científica e tecnológica ${ }^{11}$.

O disposto neste artigo aplica-se somente às importações realizadas pelo Conselho Nacional de Desenvolvimento Científico e Tecnológico - CNPq, por cientistas, por pesquisadores, por Instituição Científica, Tecnológica e de Inovação - ICT e por entidades sem fins lucrativos ativos no fomento, na coordenação ou na execução de programas de pesquisa científica e tecnológica, de inovação ou de ensino e devidamente credenciados pelo CNPq. ${ }^{12}$

Dessa forma, antes da promulgação da Lei da Inovação e da Lei do Bem, o pesquisador já possuía benefícios concedidos pelo Estado para fomento da sua pesquisa.

Ocorre que o Estado Empreendedor também é o Estado do bem estar social, e por isso tem que arcar com os programas que visam a manutenção do cidadão comum através dos programas sociais. Com a vinda das crises económicas, o Estado passou por dificuldade em fomentar a pesquisa ${ }^{13}$ e resolveu abrir mão de alguma receita tributária em troca do auxílio direto do empresário. Para tanto, promulgou a Lei da Inovação e a Lei do Bem, que dispõe os seguintes incentivos fiscais:

Art. 17. A pessoa jurídica poderá usufruir dos seguintes incentivos fiscais: I - dedução, para efeito de apuração do lucro líquido, de valor correspondente à soma dos dispêndios realizados no período de apuração

\footnotetext{
${ }^{11}$ Artigo $1^{\circ}$, da Lei n ${ }^{\circ} 8.010$, de 29 de março de 1990.

${ }^{12}$ Parágrafo $2^{\circ}$, do artigo $1^{\circ}$, da Lei $n^{\circ} 8.010$, de 29 de março de 1990.

${ }^{13}$ Artigo, $17^{\circ}, \S 1$ o Considera-se inovação tecnológica a concepção de novo produto ou processo de fabricação, bem como a agregação de novas funcionalidades ou características ao produto ou processo que implique melhorias incrementais e efetivo ganho de qualidade ou produtividade, resultando maior competitividade no mercado.
} 
com pesquisa tecnológica e desenvolvimento de inovação tecnológica classificáveis como despesas operacionais pela legislação do Imposto sobre a Renda da Pessoa Jurídica - IRPJ ou como pagamento na forma prevista no $\$ 2$ o deste artigo;

II - redução de $50 \%$ (cinqüenta por cento) do Imposto sobre Produtos Industrializados - IPI incidente sobre equipamentos, máquinas, aparelhos e instrumentos, bem como os acessórios sobressalentes e ferramentas que acompanhem esses bens, destinados à pesquisa e ao desenvolvimento tecnológico;

III - depreciação integral, no próprio ano da aquisição, de máquinas, equipamentos, aparelhos e instrumentos, novos, destinados à utilização nas atividades de pesquisa tecnológica e desenvolvimento de inovação tecnológica, para efeito de apuração do IRPJ e da CSLL; (Redação dada pela Lei $n^{\circ} 11.774$, de 2008)

IV - amortização acelerada, mediante dedução como custo ou despesa operacional, no período de apuração em que forem efetuados, dos dispêndios relativos à aquisição de bens intangíveis, vinculados exclusivamente às atividades de pesquisa tecnológica e desenvolvimento de inovação tecnológica, classificáveis no ativo diferido do beneficiário, para efeito de apuração do IRPJ;

V-(Revogado pela de Medida Provisória $n^{o}$ 497, de 2010)

$V I$ - redução a 0 (zero) da alíquota do imposto de renda retido na fonte nas remessas efetuadas para o exterior destinadas ao registro e manutenção de marcas, patentes e cultivares.

Por sua vez, a já mencionada Lei no 11.196/2005 (Lei do Bem), dispõe de seis benefícios fiscais:

\begin{abstract}
Art. 21. A União, por intermédio das agências de fomento de ciências e tecnologia, poderá subvencionar o valor da remuneração de pesquisadores, titulados como mestres ou doutores, empregados em atividades de inovação tecnológica em empresas localizadas no território brasileiro, na forma do regulamento. (Vigência) (Regulamento)

Parágrafo único. $O$ valor da subvenção de que trata o caput deste artigo será de:

I - até $60 \%$ (sessenta por cento) para as pessoas jurídicas nas áreas de atuação das extintas Sudene e Sudam;

II - até $40 \%$ (quarenta por cento), nas demais regiões.

Art. 22. Os dispêndios e pagamentos de que tratam os arts. 17 a 20 desta Lei (Vigência) (Regulamento)

I - serão controlados contabilmente em contas específicas; $e$

II - somente poderão ser deduzidos se pagos a pessoas físicas ou jurídicas residentes e domiciliadas no País, ressalvados os mencionados nos incisos $V$ e VI do caput do art. 17 desta Lei.

Art. 23. O gozo dos benefícios fiscais e da subvenção de que tratam os arts. 17 a 21 desta Lei fica condicionado à comprovação da regularidade fiscal da pessoa jurídica.
\end{abstract}

Tal norma é regulamentada pelo Decreto $\mathrm{n}^{\circ} 5.798$, que dispõe o que a pessoa jurídica poderá usufruir: 
I - dedução, para efeito de apuração do lucro líquido, de valor correspondente à soma dos dispêndios realizados no período de apuração com pesquisa tecnológica e desenvolvimento de inovação tecnológica, classificáveis como despesas operacionais pela legislação do Imposto sobre a Renda da Pessoa Jurídica - IRPJ, ou como pagamento na forma prevista no $\$ 1$ lo deste artigo;

II - redução de cinqüenta por cento do Imposto sobre Produtos Industrializados - IPI incidente sobre equipamentos, máquinas, aparelhos e instrumentos, bem como os acessórios sobressalentes e ferramentas que acompanhem esses bens, destinados à pesquisa e ao desenvolvimento tecnológico;

III - depreciação acelerada, calculada pela aplicação da taxa de depreciação usualmente admitida, multiplicada por dois, sem prejuízo da depreciação normal das máquinas, equipamentos, aparelhos e instrumentos novos, destinados à utilização nas atividades de pesquisa tecnológica $e$ desenvolvimento de inovação tecnológica, para efeito de apuração do IRPJ; III - depreciação acelerada integral, no próprio ano da aquisição, de máquinas, equipamentos, aparelhos e instrumentos, novos, destinados à utilização nas atividades de pesquisa tecnológica e desenvolvimento de inovação tecnológica, para efeito de apuração do IRPJ e da CSLL; (Redação dada pelo Decreto ${ }^{\circ}$ 6.909, DE 2009);

IV - amortização acelerada, mediante dedução como custo ou despesa operacional, no período de apuração em que forem efetuados, dos dispêndios relativos à aquisição de bens intangíveis, vinculados exclusivamente às atividades de pesquisa tecnológica e desenvolvimento de inovação tecnológica, classificáveis no ativo diferido do beneficiário, para efeito de apuração do IRPJ;

$V$ - crédito do imposto sobre a renda retido na fonte, incidente sobre os valores pagos, remetidos ou creditados a beneficiários residentes ou domiciliados no exterior, a título de royalties, de assistência técnica ou científica e de serviços especializados, previstos em contratos de transferência de tecnologia averbados ou registrados nos termos da Lei no 9.279, de 14 de maio de 1996, nos seguintes percentuais:

a) vinte por cento, relativamente aos períodos de apuração encerrados a partir de 10 de janeiro de 2006, até 31 de dezembro de 2008;

b) dez por cento, relativamente aos períodos de apuração encerrados a partir de 1 o de janeiro de 2009, até 31 de dezembro de 2013; e

VI - redução a zero da alíquota do imposto sobre a renda retido na fonte nas remessas efetuadas para o exterior destinadas ao registro e manutenção de marcas, patentes e cultivares.

Como se pode observar, das normas acima expostas, o legislador ateve-se a controlar as formas do que usar, como usar e para que usar, visando coibir desvios de finalidade das receitas oriundas do incentivo fiscal, no entanto, não previu o controlo do objeto da pesquisa $^{14}$.

\footnotetext{
${ }^{14}$ Aqui passaremos a tratar pesquisa como inovação tecnológica. 


\section{pontěditora}

\section{CONCLUSÃO}

Espera-se que fique claro, para o leitor, que é de suma importância um estudo anterior ao investimento beneficiado pelo incentivo fiscal, para que fruto da pesquisa incentivada não seja prejudicial. Porquanto, o Estado renúncia de uma receita para fomentar o desenvolvimento económico.

O qual, por sua vez, não terá o devido alcance se o resultado da pesquisa beneficiada (o que se vê) ocasionar prejuízo em determinado seguimento empresarial (o que não se vê). Pois, considerando o exemplo utilizado no presente artigo e, conforme um estudo elaborado pela empresa de marketing Juniper Research, existe a expectativa de prejuízo de bilhões de dólares em lucro nos próximos quatro anos no setor de media digital, em função de produtos inovadores.

\section{REFERÊNCIAS}

BRASIL. Constituição da República Federativa do Brasil de 1988. Disponível em: <https://goo.gl/6ueXqp>. Acesso em: 13 jul. 2017.

Lei $\mathrm{n}^{\circ} 10.973$, de 2 de dezembro de 2004. Dispõe sobre incentivos à inovação e à pesquisa científica e tecnológica no ambiente produtivo e dá outras providências. Disponível em: 〈https://goo.gl/z5MrTk>. Acesso em: 13 jul. 2017.

Lei $\mathrm{n}^{\circ}$ 13.243, de 11 de janeiro de 2016. Dispõe sobre estímulos ao desenvolvimento científico, à pesquisa, à capacitação científica e tecnológica e à inovação e altera a Lei no 10.973, de 2 de dezembro de 2004, a Lei no 6.815, de 19 de agosto de 1980, a Lei no 8.666, de 21 de junho de 1993, a Lei no 12.462, de 4 de agosto de 2011, a Lei no 8.745, de 9 de dezembro de 1993, a Lei no 8.958, de 20 de dezembro de 1994, a Lei no 8.010, de 29 de março de 1990, a Lei no 8.032, de 12 de abril de 1990, e a Lei no 12.772, de 28 de dezembro de 2012, nos termos da Emenda Constitucional no 85, de 26 de fevereiro de 2015. Disponível em: <https://goo.gl/FTyCqB>. Acesso em: 13 jul. 2017.

Decreto $\mathrm{n}^{\circ} 5.563$, de 11 de outubro de 2005. Regulamenta a Lei $\mathrm{n}^{\circ} 10.973$, de 2 de dezembro de 2004, que dispõe sobre incentivos à inovação e à pesquisa científica e tecnológica no ambiente produtivo, e dá outras providências. Disponível em: <https://goo.gl/LwBsn9>. Acesso em: 13 jul. 2017.

Lei $n^{\circ}$ 8.010, de 29 de março de 1990. Dispõe sobre importações de bens destinados à pesquisa científica e tecnológica, e dá outras providências. Disponível em: <https://goo.gl/BCD4LX>. Acesso em: 13 jul. 2017.

Lei $\mathrm{n}^{\mathrm{o}}$ 11.196, de 21 de novembro de 2005. Institui o Regime Especial de 


\section{pontěditora}

Tributação para a Plataforma de Exportação de Serviços de Tecnologia da Informação REPES, o Regime Especial de Aquisição de Bens de Capital para Empresas Exportadoras - RECAP e o Programa de Inclusão Digital; dispõe sobre incentivos fiscais para a inovação tecnológica; altera o Decreto-Lei no 288, de 28 de fevereiro de 1967, o Decreto no 70.235, de 6 de março de 1972, o Decreto-Lei no 2.287, de 23 de julho de 1986, as Leis nos 4.502, de 30 de novembro de 1964, 8.212, de 24 de julho de 1991, 8.245, de 18 de outubro de 1991, 8.387, de 30 de dezembro de 1991, 8.666, de 21 de junho de 1993, 8.981, de 20 de janeiro de 1995, 8.987, de 13 de fevereiro de 1995, 8.989, de 24 de fevereiro de 1995, 9.249, de 26 de dezembro de 1995, 9.250, de 26 de dezembro de 1995, 9.311, de 24 de outubro de 1996, 9.317, de 5 de dezembro de 1996, 9.430, de 27 de dezembro de 1996, 9.718, de 27 de novembro de 1998, 10.336, de 19 de dezembro de 2001, 10.438, de 26 de abril de 2002, 10.485, de 3 de julho de 2002, 10.637, de 30 de dezembro de 2002, 10.755, de 3 de novembro de 2003, 10.833, de 29 de dezembro de 2003, 10.865, de 30 de abril de 2004, 10.925, de 23 de julho de 2004, 10.931, de 2 de agosto de 2004, 11.033, de 21 de dezembro de 2004, 11.051, de 29 de dezembro de 2004, 11.053, de 29 de dezembro de 2004, 11.101, de 9 de fevereiro de 2005, 11.128, de 28 de junho de 2005, e a Medida Provisória no 2.199-14, de 24 de agosto de 2001; revoga a Lei no 8.661, de 2 de junho de 1993, e dispositivos das Leis nos 8.668, de 25 de junho de 1993, 8.981, de 20 de janeiro de 1995, 10.637, de 30 de dezembro de 2002, 10.755, de 3 de novembro de 2003, 10.865, de 30 de abril de 2004, 10.931, de 2 de agosto de 2004, e da Medida Provisória no 2.158-35, de 24 de agosto de 2001; e dá outras providências. Disponível em: 〈https://goo.gl/iMz53N〉. Acesso em: 13 jul. 2017.

Decreto $\mathrm{n}^{\circ} 5.798$, de 7 de junho de 2006. Regulamenta os incentivos fiscais às atividades de pesquisa tecnológica e desenvolvimento de inovação tecnológica, de que tratam os arts. 17 a 26 da Lei no 11.196, de 21 de novembro de 2005. Disponível em: <https://goo.gl/W7EgjB>. Acesso em: 13 jul. 2017.

ASSOCIAÇÃO BRASILEIRA DE NORMAS TÉCNICAS. NBR 10520. Informação e documentação: citações em documentos: apresentação. Rio de Janeiro, 2002. Disponível em: <https://goo.gl/SCbJhn>. Acesso em: 13 jul. 2017.

NBR 12225. Informação e documentação - Lombada - Apresentação. Rio de Janeiro, 2004. Disponível em: <https://goo.gl/eQtvE2>. Acesso em: 13 jul. 2017.

NBR 14724. Informação e documentação — Trabalhos académicos Apresentação. Rio de Janeiro, 2005. Disponível em: 〈https://goo.gl/rMz71Y〉. Acesso em: 13 jul. 2017.

NBR 15287. Informação e documentação - Projeto de pesquisa Apresentação. Rio de Janeiro, 2005. Disponível em: 〈https://goo.gl/7TwZhD>. Acesso em: 13 jul. 2017.

NBR 6021. Informação e documentação - Publicação periódica científica impressa - Apresentação. Rio de Janeiro, 2003. Disponível em: <https://goo.gl/zLFZoR>. Acesso em: 13 jul. 2017. 


\section{pontěditora}

. NBR 6022. Informação e documentação - Artigo em publicação periódica científica impressa - Apresentação. Rio de Janeiro, 2002. Disponível em: <https://goo.gl/cj91Zc〉. Acesso em: 13 jul. 2017.

NBR 6023. Informação e documentação - Referências - Elaboração. Rio de Janeiro, 2002. Disponível em: <https://goo.gl/ktLCp5>. Acesso em: 13 jul. 2017.

NBR 6024. Informação e documentação - Numeração progressiva das seções de um documento escrito - Apresentação. Rio de Janeiro, 2003. Disponível em: <https://goo.gl/PN5fBc>. Acesso em: 13 jul. 2017.

NBR 6027. Informação e documentação - Sumário - Apresentação. Rio de Janeiro, 2003. Disponível em: 〈https://goo.gl/bDBYPx>. Acesso em: 13 jul. 2017.

NBR 6028. Informação e documentação - Resumo - Apresentação. Rio de Janeiro, 2003. Disponível em: <https://goo.gl/bshzXN>. Acesso em: 13 jul. 2017.

NBR 6029. Informação e documentação - Livros e folhetos - Apresentação. Rio de Janeiro, 2006. Disponível em: 〈https://goo.gl/uwJBMd〉. Acesso em: 13 jul. 2017.

NBR 6032. Abreviação de títulos de periódicos e publicações seriadas. Rio de Janeiro, 1989. Disponível em: 〈https://goo.gl/d3iQtn〉. Acesso em: 13 jul. 2017.

NBR 6034. Informação e documentação - Índice - Apresentação. Rio de Janeiro, 2004. Disponível em: 〈https://goo.gl/EilygV〉. Acesso em: 13 jul. 2017.

MAZZUCATO, Mariana. O Estado Empreendedor - Desmascarando o Mito do Setor Público Vs. o Setor Privado. Portfolio - Penguin, 2014.

MICKLETHWAIT, John. A quarta revolução: A corrida global para reinventar o Estado. Portfolio - Penguin, 2015

PEREIRA, José Matias. Gestão de inovação: a lei de inovação tecnológica como ferramenta de apoio às políticas industrial e tecnológica do Brasil. São Paulo. RAEeletrónica, 2005. Disponível em: 〈https://goo.gl/N9iEFE〉. Acesso em: 13 jul. 2017.

SALIM, Marcel. Por que o Brasil não está no ranking das 100 cidades inovadoras. Exame.com. Disponível em: 〈https://goo.gl/t16dY9>. Acesso em: 13 jul. 2017.

Pesquisa de Inovação. IBGE, 2014. Disponível em: 〈https://goo.gl/9mErjz〉. Acesso em: 13 jul. 2017.

MEDIATI, Nick. AdBlock, AdBlock Plus arrives for Windows 10 Insider users. PCWORLD. 2016. Disponível em: 〈https://goo.gl/RyF1MR〉. Acesso em: 13 jul. 2017.

LARKIN, Erik. Adblock Plus. PCWORLD. 2016. Disponível em: <https://goo.gl/mdC4LX>. Acesso em: 13 jul. 2017. 


\section{pontěditora}

Relatório - investimentos digitais. PWC e IAB US. 2015. Disponível em: <https://goo.gl/JGyhyD>. Acesso em: 13 jul. 2017.

Relatório - números de investimento em mídia online 2013-2014. IAB Brasil. Disponível em: 〈https://goo.gl/JGyhyD>. Acesso em: 13 jul. 2017.

Relatório - indicadores da internet no Brasil - dados nov-2013. Comitê de Métricas de Audiência e Pesquisa de Mercado. Disponível em: 〈https://goo.gl/JGyhyD>. Acesso em: 13 jul. 2017.

I Censo Legislativo 2005. Programa Interlegis. 2008. Disponível em: <https://goo.gl/FNM7jR>. Acesso em: 13 jul. 2017.

Relatório - digital retail marketing: coupons, advertising \& consumer engagement 2016-2020 - Disponível em: 〈https://goo.gl/rTgoxf〉. Acesso em: 13 jul. 2017.

Relatório - worldwide digital advertising 2016-2020 - Disponível em: <https://goo.gl/ioSdTx>. Acesso em: 13 jul. 2017.

Relatório - digital, social e mobile de 2015. A agência de marketing social We Are Social. Disponível em: 〈https://goo.gl/HTBTgD>. Acesso em: 13 jul. 2017.

Pesquisa Nacional por Amostra de Domicílios - Acesso a internet e posse de telefone móvel celular para uso pessoal. IBGE, 2011. Disponível em: 〈https://goo.gl/QC2Gtd〉. Acesso em: 13 jul. 2017. 